\title{
Niort - Parking du Moulin du Milieu
}

\section{Annie Bolle}

URL : http://journals.openedition.org/adlfi/3326

ISSN : 2114-0502

Éditeur

Ministère de la culture

\section{Référence électronique}

Annie Bolle, "Niort - Parking du Moulin du Milieu », ADLFI. Archéologie de la France - Informations [En ligne], Poitou-Charentes, mis en ligne le 01 mars 2009, consulté le 20 avril 2019. URL : http:// journals.openedition.org/adlfi/3326

Ce document a été généré automatiquement le 20 avril 2019.

(c) Ministère de la Culture et de la Communication, CNRS 


\title{
Niort - Parking du Moulin du Milieu
}

\author{
Annie Bolle
}

\section{Identifiant de l'opération archéologique : 204870}

Date de l'opération : 2009 (EX)

1 En amont de la réalisation d'un bassin de récupération des eaux pluviales et usées d'une capacité de $3000 \mathrm{~m}^{3}$, un diagnostic archéologique a été réalisé par l'Inrap en juillet 2008. Le projet de construction, d'une superficie de $1300 \mathrm{~m}^{2}$, est localisé dans un méandre de la Sèvre niortaise, au pied des remparts de la ville et du donjon du XII ${ }^{e}$ s., en face d'une des entrées de l'enceinte et du port médiéval. Ce port, devenu difficile d'accès en raison de son ensablement progressif et de l'implantation de moulins, sera remplacé à la fin de la guerre de Cent Ans, alors que la ville de Niort est définitivement reprise aux Anglais. La fouille se situe sur le « Moulin du Milieu », attesté dès le XIII" s.

2 Cette situation en bord de Sèvre a imposé des contraintes techniques et la fouille s'est déroulée en deux phases, la seconde correspondant au dégagement de la partie basse du site après l'installation de butons métalliques. La fouille a permis d'étudier différents états du moulin, abandonné et détruit dans le courant du XXe $\mathrm{s}$., et les activités artisanales et industrielles (notamment fonderie, tannerie, faïencerie) qui se sont succédé depuis la fin du Moyen Âge.

3 L'analyse du comblement du bras de Sèvre qui alimentait le moulin et de ses berges a permis de comprendre l'origine et l'évolution de la topographie de cet îlot. Les rives ont été aménagées pour permettre l'installation des tanneurs. Le travail de la peau a été une des principales activités de Niort. Les échanges développés très tôt avec le Canada ont permis aux tanneurs d'obtenir des peaux de très bonne qualité. La chamoiserie se développe et assurera une prospérité à la ville.

4 Le «Moulin du Milieu» se situe au coeur de l'essor économique lié à la révolution industrielle. C'est là que s'installe la fonderie «Lasseron et Legrand» qui y fabrique des ponts en fonte et des machines à vapeur. C'est en bord de Sèvre que se concentre la zone industrielle de Niort, attirant de très nombreux ouvriers. 
5 Exemple rare dans la région Poitou-Charentes d'archéologie industrielle, la fouille du «Moulin du Milieu » retrace un pan de l'histoire moderne de la ville et du milieu ouvrier. La dernière activité du site, la faïencerie des "Frères Gautier » a livré une très grande quantité de moules, ratés de cuisson, outils et essais divers (écriture, dessin, couleur). Elle permet une étude d'archéologie expérimentale basée sur l'analyse comparative entre dépotoir et production réelle. Etonnamment, le souvenir de ces activités s'est effacé de la mémoire des Niortais avec la destruction de cette architecture industrielle.

6 (Fig. $n^{\circ} 1$ : Vue générale de la fouille) et (Fig. $n^{\circ} 2:$ Sols successifs et réaménagements des quais)

7 Bolle Annie

\section{ANNEXES}

Fig. $n^{\circ} 1$ : Vue générale de la fouille

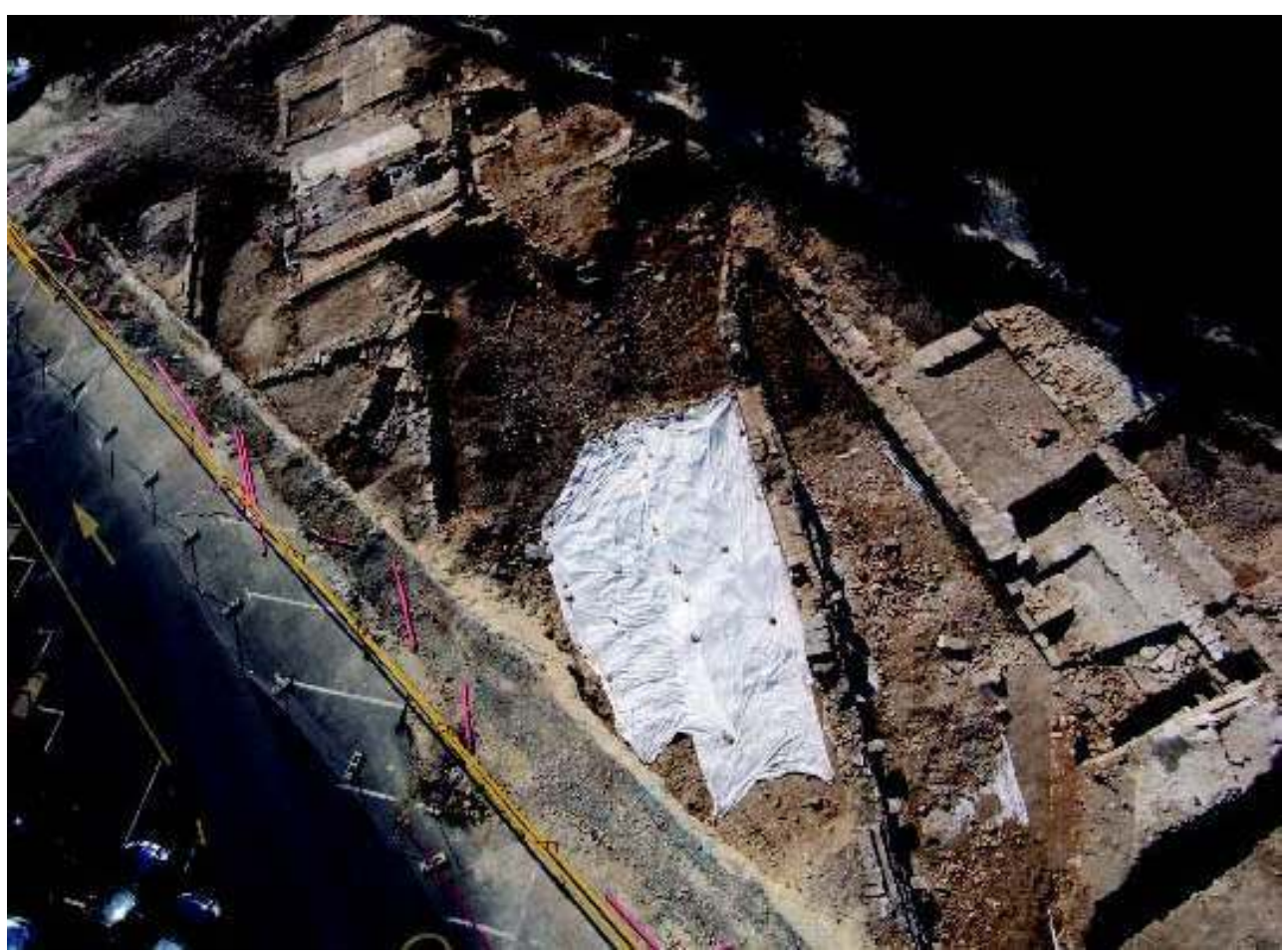

Auteur(s) : Devis, A.. Crédits : Devis, A. (2009) 
Fig. $n^{\circ} 2$ : Sols successifs et réaménagements des quais

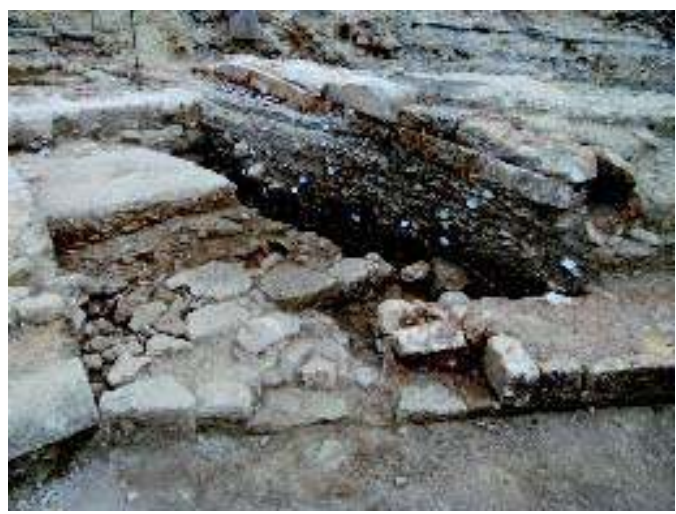

Auteur(s) : Torchut, J.-S.. Crédits : Torchut, J.-S. (2009)

INDEX

operation Expertise (EX)

Index géographique : Poitou-Charentes, Deux-Sèvres (79), Niort

Thèmes : activités commerciales, aménagement de berge, archéologie expérimentale, archéologie industrielle, artisanat, chamois, enceinte, faïence, fleuve, fonderie, moulin, peau, port, tannerie

Index chronologique : ép. contemporaine, Moyen Âge, Temps Modernes

\section{AUTEURS}

\section{ANNIE BOLLE}

INRAP 